\title{
DO EXTRATIVISMO A PRODUÇÃO: EXPERIÊNCIA DE PISCICULTURA EM COMUNIDADES RIBEIRINHAS DE CURRALINHO - MARAJÓ (PA)
}

\author{
Talita Vieira Aranha ${ }^{1}$ \\ Raimundo Aderson Lobão
}

\begin{abstract}
RESUMO
O projeto foi desenvolvido no município de Curralinho, localizado no arquipélago do Marajó na microrregião denominada furo de Breves, em quatro comunidades: Bela Pátria, Piedade, Pagão e Canaticu. Na proposta de inserção da piscicultura no sistema de produção familiar, num contexto de comunidades essencialmente extrativistas, verificando-se na piscicultura uma alternativa de oferta de alimento assim como fonte de renda para a região. Compreendendo os principais aspectos que interferem como desafios e oportunidades no fortalecimento e criação de novas frentes de expansão econômica produtiva na região. O Projeto de incentivo a piscicultura nas comunidades ribeirinhas no município de Curralinho, surgiu de apelações de famílias a partir de questionamentos quanto à possibilidade dessa prática dentro de suas pequenas propriedades. Uma vez que sempre pautou-se em discussões do Plano de Desenvolvimento Territorial do Arquipélago do Marajó, incentivo à produção como principais diretrizes.
\end{abstract}

Palavras-chave: Piscicultura familiar. Curralinho. Marajó.

\begin{abstract}
The project was developed in the municipality of Curralinho, located in the archipelago of Marajó in the borehole of Breves, in four Bela Pátria, Piedade, Pagão and Canaticu communities. In the proposal of insertion of fish farming in the family production system, in a context of essentially extractive communities, there is an alternative of food supply as well as a source of income for the region in fish farming. Understanding the main aspects that interfere as challenges and opportunities in strengthening and creating new fronts of productive economic expansion in the region. The Project to encourage fish farming in riparian communities in the municipality of Curralinho, Marajó, arose from the appeals of some families based on questions about the possibility of practicing this activity within their small properties. Since it has always been based on discussions of the Plan of Territorial Development of the Marajó Archipelago, incentives to other productive fronts as main guidelines.
\end{abstract}

Keywords: Family fish farm. Curralinho. Marajó.

\section{INTRODUÇÃO}

A região do Arquipélago do Marajó constituiu a maior ilha flúvio-marítimo do mundo com 49.606 $\mathrm{Km}^{2}$ de área, integralmente no estado Pará (PDTS, 2007). Ainda que alguns dos 16 municípios que compõe o arquipélago tenham relação intrínseca com o estado do Amapá, devido à sua localização geográfica.

\footnotetext{
${ }^{1}$ Engenheira de Pesca (UFRA), Discente do Programa de Pós -graduação em Desenvolvimento Rural e Gestão de Empreendimento Agroalimentares (IFPA) E-mail: talitaranhapesca@gmail.com

2 Doutor em Ecologia de Recursos Aquáticos (Universidade Federal de São Carlos, Professor Instituto Sócio ambiental e dos Recursos Hídricos (UFRA) E-mail: adersonlobao@ gmail.com
} 
O arquipélago do Marajó caracteriza-se por ambientes distintos entre florestas inundáveis de grande potencial econômico de espécies madeireiras, não madeireiras e área de campos. Assim Salera Júnior (2011) ressalta que no ambiente de florestas, o açaí (Euterpe oleracea) destaca-se como símbolo da dieta alimentar e economia local das comunidades tradicionais.

Contudo, vale ressaltar que nem sempre o açaí foi o principal produto da economia marajoara. Desde o início da colonização, o desenvolvimento econômico da Ilha de Marajó sempre foi alicerçado no extrativismo. A pesca comercial, a extração da borracha e a exploração de madeira foram alguns dos produtos da floresta que promoveram ciclos de desenvolvimento nessa parte do norte brasileiro (SALERA JÚNIOR, 2011.p.15)

No contexto buscou-se inicialmente compreender os principais aspectos que interferem como desafios e oportunidades no fortalecimento e criação de novas frentes de expansão econômica produtiva na região.

O Plano de Desenvolvimento Territorial Sustentável do Arquipélago do Marajó, estabeleceu entre suas diretrizes, a elevação dos índices de desenvolvimento na região, pautados em vários campos de atuação, verificando-se principalmente o fortalecimento da segurança alimentar, além de geração de trabalho e renda, por meio de apoio no agroextrativismo e empreendimentos de base familiar.

Trabalhou-se a inserção da piscicultura no sistema de produção familiar, num contexto de comunidades essencialmente extrativistas, verificando-se na piscicultura uma alternativa de oferta de alimento assim como fonte de renda para a região. Gomes, et al (2013), afirma que a criação de peixes em pequenas propriedades rurais pode gerar receita com a comercialização da produção, além de incrementar na qualidade nutricional da dieta familiar.

Observando a piscicultura como a atividade de potencial a ser inserida na realidade local, existiu sempre a preocupação com os paradigmas culturais e regionais dessas famílias, uma vez que modificações no sistema de produção causam implicações no uso do espaço e de mão de obra, bem como na reorganização das atividades e na economia do estabelecimento familiar (SILVA JUNIOR, 2016). Sendo ainda observado, que uma reorganização do processo produtivo provoca alteração na vida familiar, que pode significar aumento do desgaste físico da força de trabalho além da necessidade de recrutamento dos filhos mais novos (ALENCAR, 1997).

A unidade de produção ou estabelecimento familiar não é só um espaço de produção, é também o patrimônio da família. Através da produção ocorre a relação socioeconômica do homem e de família com o meio externo, sendo o 
estabelecimento ao mesmo tempo local de trabalho e de vivencia familiar (SILVA JUNIOR, 2016. p. 15).

Partindo da lógica de intervenção, é importante além do enfoque técnico produtivo, a visão e o significado da proposta para essas famílias. Considerando os aspectos que influenciam direta e indiretamente nessas comunidades, como por exemplo a atividade pesqueira que implica em ocupações distintas do ribeirinho ou pescador conforme as estações da natureza e conforme regimes de marés e/ou chuvas (FERNANDES; FERNADES 2015). Ou seja, é necessário o entendimento e/ou apropriação devida desse conhecimento de sazonalidade, para implementação mais eficiente de sistemas de produção nessas comunidades. Desta forma de acordo com Fernandes \& Fernandes, (2015), torna-se adequado a associação do saber tradicional das comunidades com o conhecimento escolarizado, podendo ter mais efetividade na consecução dos objetivos propostos.

\section{1. ÁREA DE ESTUDO}

O projeto foi desenvolvido no município de Curralinho, localizado no arquipélago do Marajó na microrregião denominada furo de Breves sob coordenadas $01^{\circ} 48^{\prime} 49^{\prime \prime} \mathrm{S}$ e 4947’43”, tendo como limites ao norte o município de Breves, ao sul o Rio Pará e Baía das Bocas, e ao leste São Sebastião da Boa Vista. (Figura 1). População estimada em 33.983 habitantes segundo dados do IBGE, 2016. As atividades foram desenvolvidas em 4 comunidades: Bela Pátria, Piedade, Pagão e Canaticu. 
Figura 1 - Mapa de localização do local de estudo

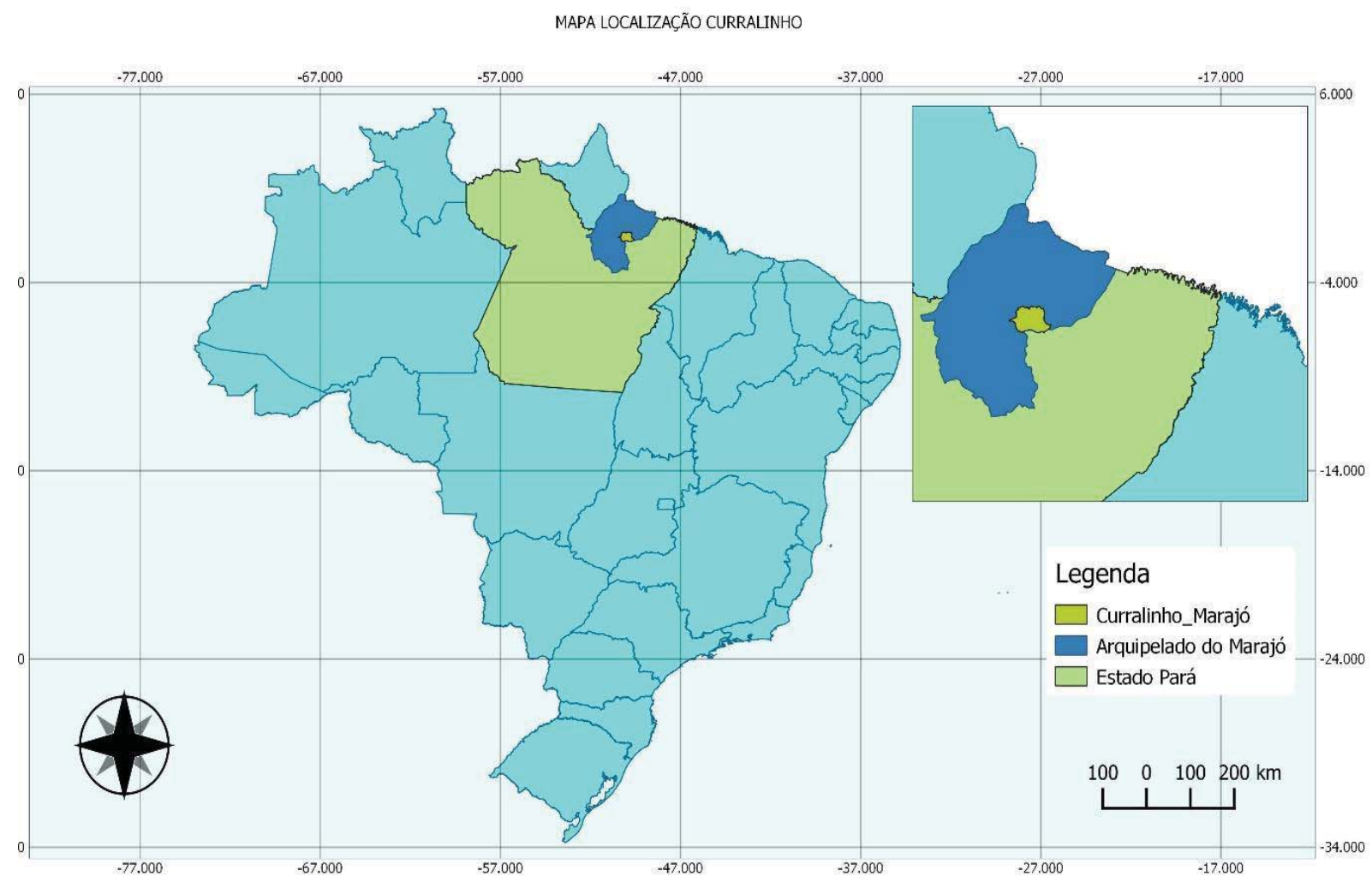

Fonte: Talita Guimaraes (Qgiz 3.2), 2018.

O município está dentro da Reserva Extrativista Terra Grande - Pracuúba que abrange também o município de São Sebastião da Boa Vista, foi criada pelo Decreto de 05 de junho de 2006, com área de 194.695 hectares, e tem como objetivo básico proteger os meios de vida e a cultura dessas populações e assegurar o uso sustentável dos recursos naturais renováveis, tradicionalmente utilizados pela população extrativista residente na área de sua abrangência (ICMBio, 2006).

\footnotetext{
As atividades econômicas dos ribeirinhos da RESEX Terra Grande-Pracuúba se caracterizam pela extração de madeiras (virola, pracuúba, anani, jacareúba, tamacuaré etc.), frutas oleaginosas (andiroba, murumuru, pracaxi e buriti), do açaí (fruto e palmito), caça de subsistência (tatu, paca, cutia etc.), a pesca (peixes e camarões) e a produção de produtos agrícolas típicos da agricultura familiar paraense (mandioca, milho, melancia, arroz, banana etc.). (SALERA JUNIOR, 2014, p. 1).
}

Todas as informações das atividades praticadas pelas comunidades foram devidamente consideradas, tomadas a partir de vários encontros e visitas in loco antes da coleta de dados propriamente dita. 
O projeto contou com fomento por parte do Governo Federal sendo portanto de fundamental importância a verificação preliminar de viabilidade do projeto, assim como garantias de impactos positivos para essas famílias.

\section{A PROPOSTA DE INTERVENÇÃO}

Os povos e comunidades tradicionais assim denominadas e reconhecidos pelo Decreto 6.040/2007 são os principais atores objeto desse estudo, uma vez que se trata de comunidades ribeirinhas que ocupam um determinado território, no caso específicos a ilha do Marajó. Onde a proposta verificou não somente questões técnicas mais principalmente a interferência de uma nova atividade nesse contexto social.

Povos e Comunidades Tradicionais: grupos culturalmente diferenciados e que se reconhecem como tais, que possuem formas próprias de organização social, que ocupam e usam territórios e recursos naturais como condição para sua reprodução cultural, social, religiosa, ancestral e econômica, utilizando conhecimentos, inovações e práticas gerados e trans mitidos pela tradição (DECRETO 6.040/2007).

A demanda por essa nova proposta produtiva baseou-se na percepção que, as políticas públicas para a Amazônia nos últimos anos têm priorizado agentes exógenos, deixando de envolver pequenos agricultores e povos da floresta que, há anos, estão à margem da ação governamental, seja nos investimentos, no sistema de crédito ou nos meios de circulação de mercadorias (FERNANDES, 2015).

Em se tratando do Marajó, tem características marcantes como os baixos padrões de qualidade de vida facilmente constatados pelos indicadores. A falta de acesso a serviços e políticas públicas, restringem o potencial de desenvolvimento econômico sustentável. Esse preâmbulo se faz necessário no entendimento que levou a inquietação de alguns agentes locais, na percepção do distanciamento de investimentos públicos, ou seja incentivo específicos que fomentassem o desenvolvimento de sistemas produtivos na região.

O Projeto de incentivo a piscicultura nas comunidades ribeirinhas no município de Curralinho, surgiu de apelo de algumas famílias a partir de questionamentos quanto à possibilidade da prática dessa atividade dentro de suas pequenas propriedades. Uma vez que, sempre pautada em discussões do Plano de Desenvolvimento Territorial do Arquipélago do Marajó, incentivos a outras frentes produtivas como uma das principais diretrizes.

$\mathrm{O}$ anseio pela possibilidade se fortaleceu e seguiu para as discussões nos fóruns do Conselho Desenvolvimento Territorial e foi capitaneada por um grupo institucional do 
município juntamente com agentes das comunidades. Este arranjo buscou um apoio mais substanciado através de investimento e assistência técnica especializada.

A ação antecedente ao início do projeto contou com a iniciativa da organização da Central de Associações do município, EMATER, Colônia de pescadores, Sindicato dos Trabalhadores Rurais, ADEPARÁ e Secretaria Municipal de Agricultura. Além da formação de um número significante de famílias engajadas nessa proposta.

Figura 2 - Reunião do grupo de iniciativa do projeto

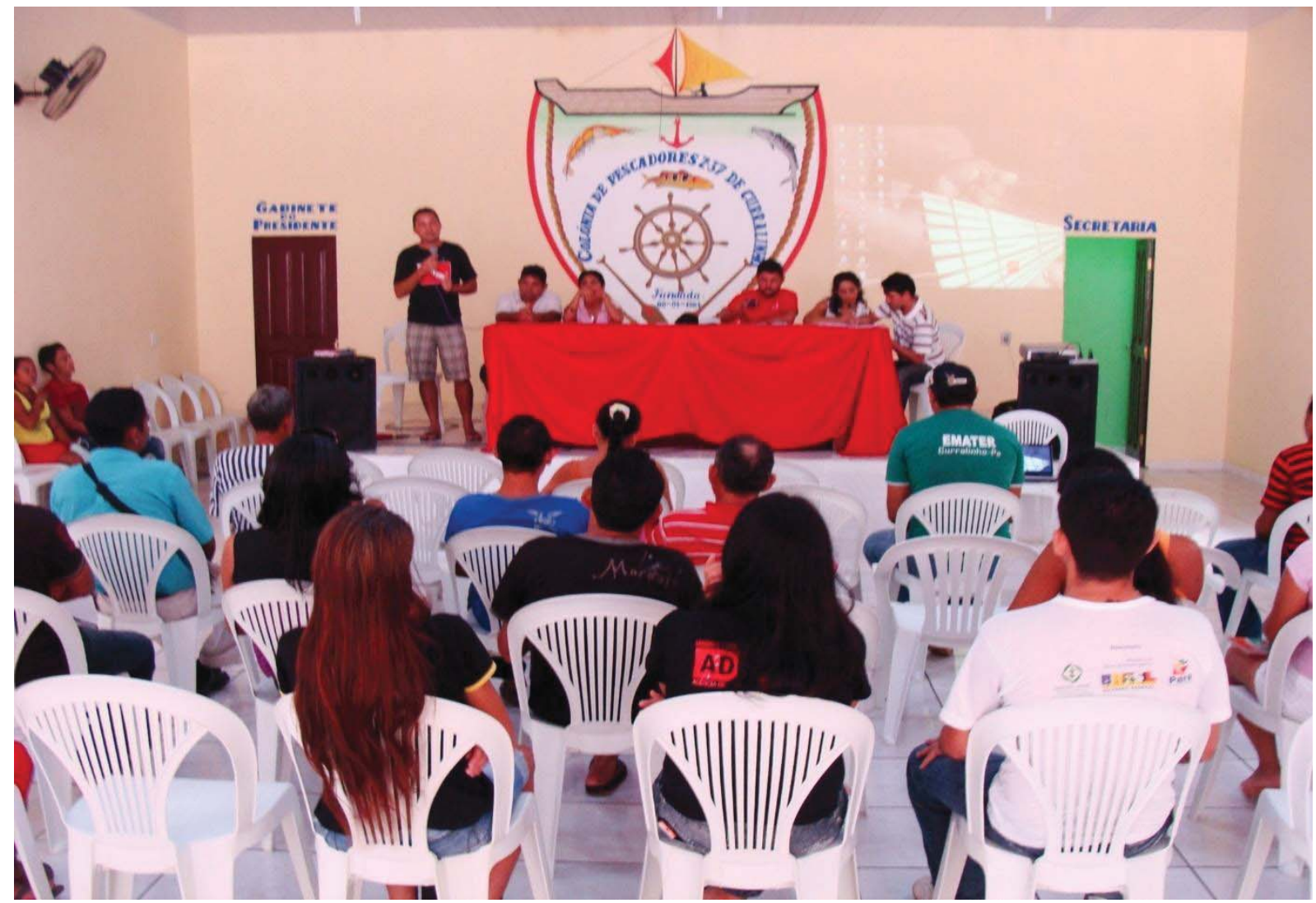

Fonte: Arquivo pessoal da autora, ano 2010.

Anterior a implantação do projeto de piscicultura familiar em Curralinho, já haviam tido algumas iniciativas de criação de peixe sem êxito, que se atribui a falta de conhecimento adequado, ou seja sem orientação e acompanhamento técnico.

Entretanto com iniciativas exitosas em outros municípios do Marajó como São Sebastião da Boa Vista, Portel e Breves que foram usados como exemplo, o ânimo foi restaurado e fortalecido para a inserção da atividade, uma vez que as comunidades são originalmente extrativistas.

A piscicultura surgiu nessa região também como uma alternativa de diminuição da pressão ambiental ocasionada por extração de madeira, promovendo razões suficiente, e 
oportunidades, que justifique a implantação de um programa de apoio e estímulo à piscicultura em pequenas propriedades (ONO \& KUBTIZA, 2010).

\section{SISTEMÁTICA DE IMPLANTAÇÃO DO PROJETO DE PISCICULTURA NAS COMUNIDADES DE CURRALINHO, MARAJÓ.}

As atividades inerentes ao projeto propriamente iniciaram-se em março de 2009, com uma grande reunião em uma das comunidades escolhidas "Bela Pátria" com a participação de um grande número de famílias, que tinham interesse e necessitavam de maiores esclarecimentos, sobre como se daria a prática de implementação do projeto.

Figura 3 - Reunião comunidade Bela Pátria, Curralinho - Marajó (PA)

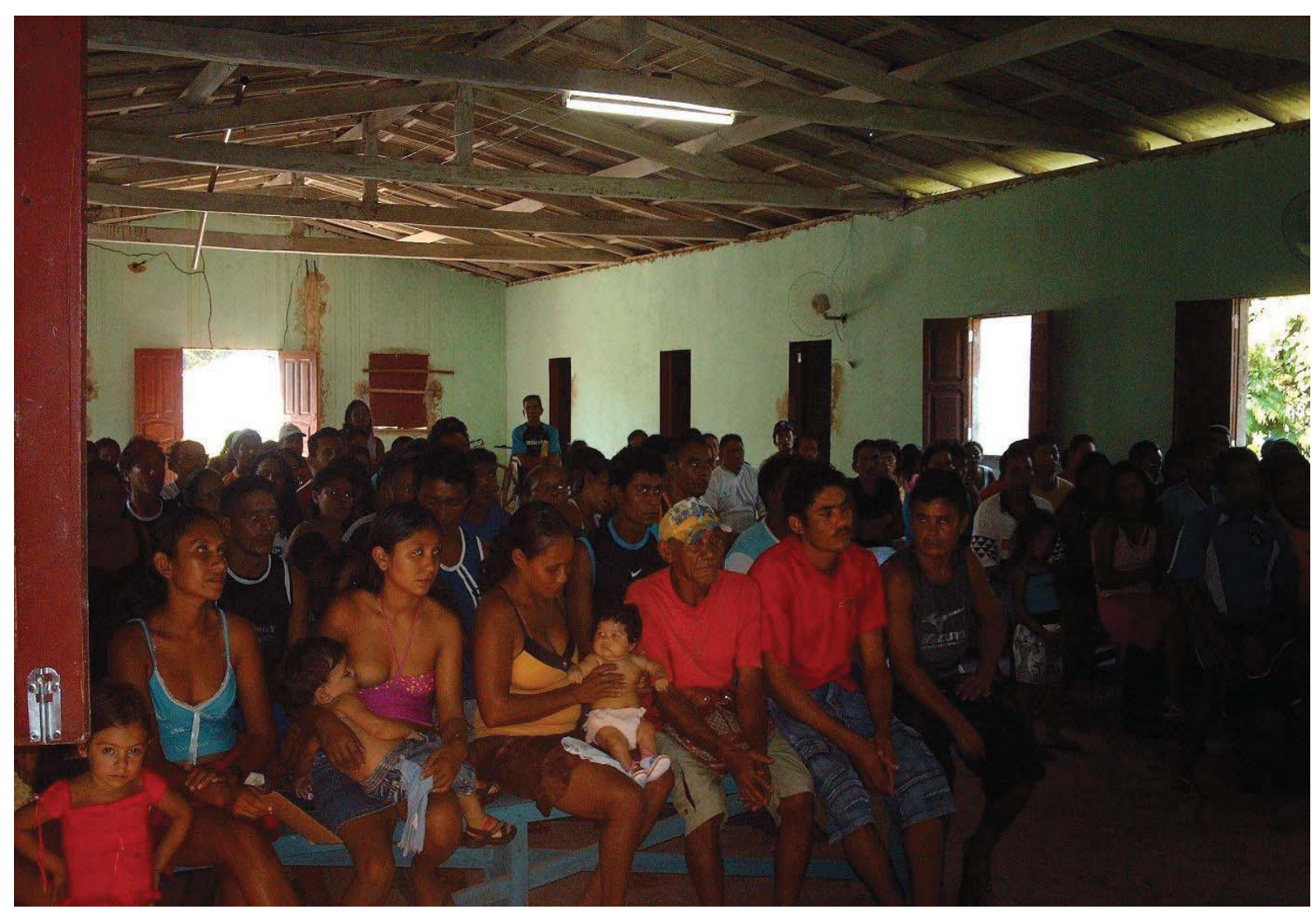

Fonte: Arquivo pessoal da autora, ano 2010.

Posterior a reunião de mobilização, foram programadas visitas técnicas nas comunidades de todas as famílias que estiveram presentes, que serviu como uma forma de cadastramento e manifestação de interesse para aderirem ao projeto. De forma que as visitas serviram para subsidiar critérios para determinação das comunidades e famílias a serem atendidas. 
As visitas foram realizadas por um período de 2 meses para seleção. Foi constituída uma equipe de trabalho, que obteve capacitação inicial para atuarem junto as famílias selecionadas. Utilizou-se para as excursões técnicas de metodologias participativas como a utilizada para a realidade em questão, a "caminhada transversal" que consiste em percorrer uma determinada área, acompanhado de informantes locais que conheçam região (SOUZA, 2009).

Figura 4 - Visitas as famílias

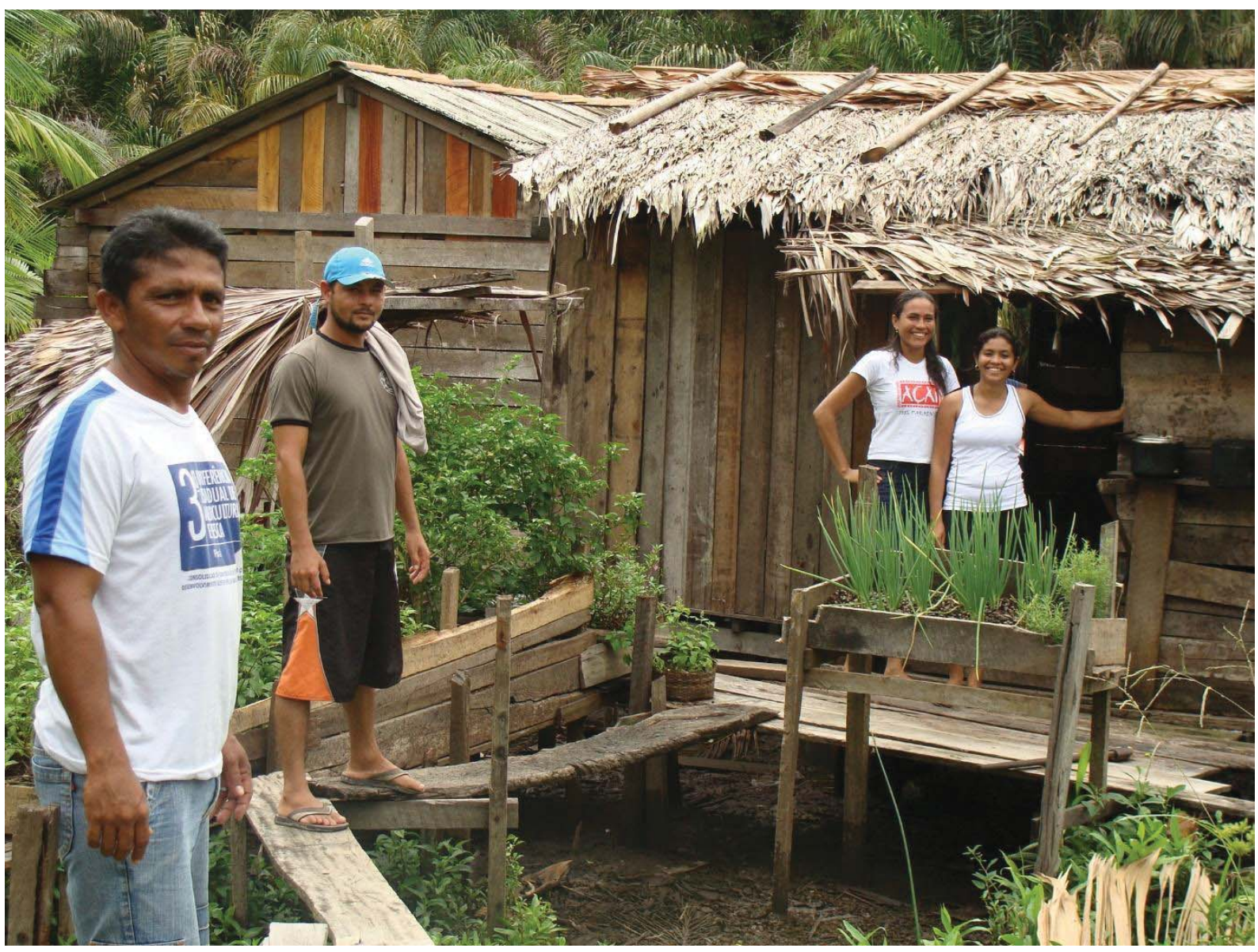

Fonte: Emater/Pa, ano 2010.

Os critérios preconizados foram distribuídos em 2 eixos temáticos: a) Técnico e b) socioambiental, disposto da seguinte forma: 
Quadro 1 - Critério de seleção das famílias

\begin{tabular}{c|c}
\hline Técnico & Socioambiental \\
\hline $\begin{array}{c}\text { Viabilidade do local de implantação dos } \\
\text { tanques }\end{array}$ & $\begin{array}{c}\text { Estabelecimentos familiares com áreas } \\
\text { degradadas }\end{array}$ \\
\hline $\begin{array}{c}\text { Interferência do regime de maré na } \\
\text { propriedade }\end{array}$ & $\begin{array}{c}\text { Fontes de renda das famílias (atividades e } \\
\text { programas sociais) }\end{array}$ \\
\hline Participação das capacitações & $\begin{array}{c}\mathrm{N}^{\mathbf{0}} \text { de jovens nas famílias com } \\
\text { possibilidade de engajamento da atividade }\end{array}$ \\
\hline
\end{tabular}

Fonte: Ministério da Pesca e Aquicultura - MPA, ano 2010.

As atividades posteriores a seleção das familias, foram para construção dos viveiros, e cronograma de povoamento com os alevinos de tambaqui (Colossoma macropomum) a espécie determinada para o cultivo devido as determinações da legislação vigente sob a IN SEMMAS No 004/2013 que revogou a Instrução Normativa no 9, de 16 de maio de 2008, a qual dispõe sobre as espécies permitidas para cultivo no estado do Pará.

Foram selecionadas 50 familias, sendo apenas 26 para escavação imediata de tanques com a apoio da Secretaria de Agricultura do município, e as demais com o fomento do Projeto de apoio a piscicultura familiar do Ministério da Pesca e Aquicultura, que previa insumos e acompanhamento para um ciclo de cultivo, no caso específico foi de 9 meses devido ao da iniciativa.

A capacitação dos atores (famílias e agentes de assistência técnica), constou de palestras e apresentação de vídeos sobre a preparação para a implantação da piscicultura familiar, mostrando desde a limpeza da área, calagem, fertilização do viveiro e questões ambientais ligadas a atividade. Posteriormente, as familias foram orientadas sobre como realizar semanalmente o monitoramento da qualidade da água dos viveiros, fazendo uso do kit colorimétrico doado pelo projeto.

\section{ASPECTOS TÉCNICOS DA ATIVIDADE IMPLANTADA}

Os alevinos de tambaqui foram adquiridos no laboratório Piscicultura 18, localizada no município de Igarapé-Açú no $\mathrm{Km} \mathrm{18}$, fazendo um transporte até as comunidades de destino por aproximadamente 24 horas desde a capital Belém. Prevendo a dificuldade de logística foi 
construído um viveiro em uma propriedade na sede da cidade de Curralinho para servir de base de alevinagem e distribuição, esta ação foi fundamental para viabilidade do projeto.

Ficou determinado de no máximo 2 viveiros por propriedade com área de até $100 \mathrm{~m}^{2} \mathrm{e}$ profundidade de 1,3 a 1,5 m, com baixa densidade de estocagem variando entre 150 a 200 peixes, produzindo entre 180 a $200 \mathrm{~kg}$ de peixe por viveiro. A qualidade da água foi analisada antes do povoamento e se manteve em condições adequadas, ou seja, dentro dos parâmetros exigidos para o cultivo. A característica é de águas barrentas, denominadas águas brancas típicas da região do Marajó devido à grande sedimentação e lixiviação da vegetação.

Tabela 1. Qualidade de água dos viveiros nas propriedades visitadas

\begin{tabular}{cccc}
\hline Variável & Unidade & Ideal & Frequência \\
\hline Oxigênio dissolvido & $6 \mathrm{mg} / \mathrm{L}$ & $5-8$ & quinzenal \\
\hline PH & 6 & $6,5-8$ & quinzenal \\
\hline Temperatura da água & $25-28^{\circ} \mathrm{C}$ & $25-30$ & quinzenal \\
\hline Transparência & 1,8 a $2 \mathrm{~m}$ & $>3$ & quinzenal \\
\hline
\end{tabular}

Fonte: adaptada a partir de dados obtidos em pesquisa de campo - Fevereiro de 2010.

As especificações técnicas estão fundamentadas em dados para produção de tambaqui, Colossoma macropomum (Cuvier,1818) na primeira fase de produção das propriedades do município de Curralinho. O tambaqui é uma espécie nativa que ocorre naturalmente nas bacias do Rio Amazonas, sendo principal espécie cultivada em toda região amazônica (BALDISSEROTTO, GOMES 2005 op cit VAL et al 2000).

O tambaqui Colossoma macropomum (Cuvier,1818), pode atingir $1 \mathrm{~m}$ de comprimento padrão (cp) e pesar $30 \mathrm{Kg}$, pertence à família Characidae e gênero Colossoma. É comumente encontrado da foz do rio Xingu, no estado do Pará, até o médio rio Ucaiali, no Peru. É também encontrado ao longo dos tributários de água barrentas do rio Amazonas e nas partes baixas dos tributários de águas clara e negras. (BALDISSEROTTO, GOMES, 2005 p. 176). 
Tabela 2. Especificações técnicas do projeto

Tambaqui (Colossoma macropomum)

\begin{tabular}{l|c|c}
\hline Especificações & & Unidade \\
\hline Es truturas & & \\
\hline Número de viveiros & 150 & \\
\hline Dimensão media dos viveiros & 100 & viveiros \\
\hline & & $\mathrm{m}^{2}$ \\
\hline Dados de cultivo & & \\
\hline Duração do ciclo & & \\
\hline Densidade de estocagem inicial & 3 & $\mathrm{meses}$ \\
\hline Peso indivíduo Inicial & 30 & $\mathrm{alevinos} / \mathrm{m}^{2}$ \\
\hline Sobrevivência & 80 & $\mathrm{gramas}$ \\
\hline Arraçoamento & 3 & $\mathrm{vezes} \mathrm{ao} \mathrm{dia}$ \\
\hline Peso final de indivíduo & 1,2 & $\mathrm{~kg}$ \\
\hline Conversão alimentar & 1,8 & $\mathrm{dias}$ \\
\hline Intervalo entre as biometrias (dias) & 30 & $\mathrm{~kg} / \mathrm{m}^{2}$ \\
\hline Densidade de estocagem final & 1,2 & $\mathrm{ciclos}$ \\
\hline Ciclos por ano & 1 & $\mathrm{ciclos}$ \\
\hline Vigência do projeto & 1 & $\mathrm{~kg}$ \\
\hline Produção total/ciclo & 288 & \\
\hline
\end{tabular}

\section{RESULTADOS}

$\mathrm{Na}$ metade do ciclo de produção, foi gerado um boletim informativo acerca do acompanhamento do projeto junto as famílias, onde constava um gráfico ilustrativo sobre o desempenho de cada produtor quanto ao resultado do manejo. Para a percepção dos envolvidos a importância do manejo adequado, para o sucesso do cultivo e atender os resultados esperados dentro do programado pela proposta. 
Figura 5 - Boletim informativo entregue as famílias

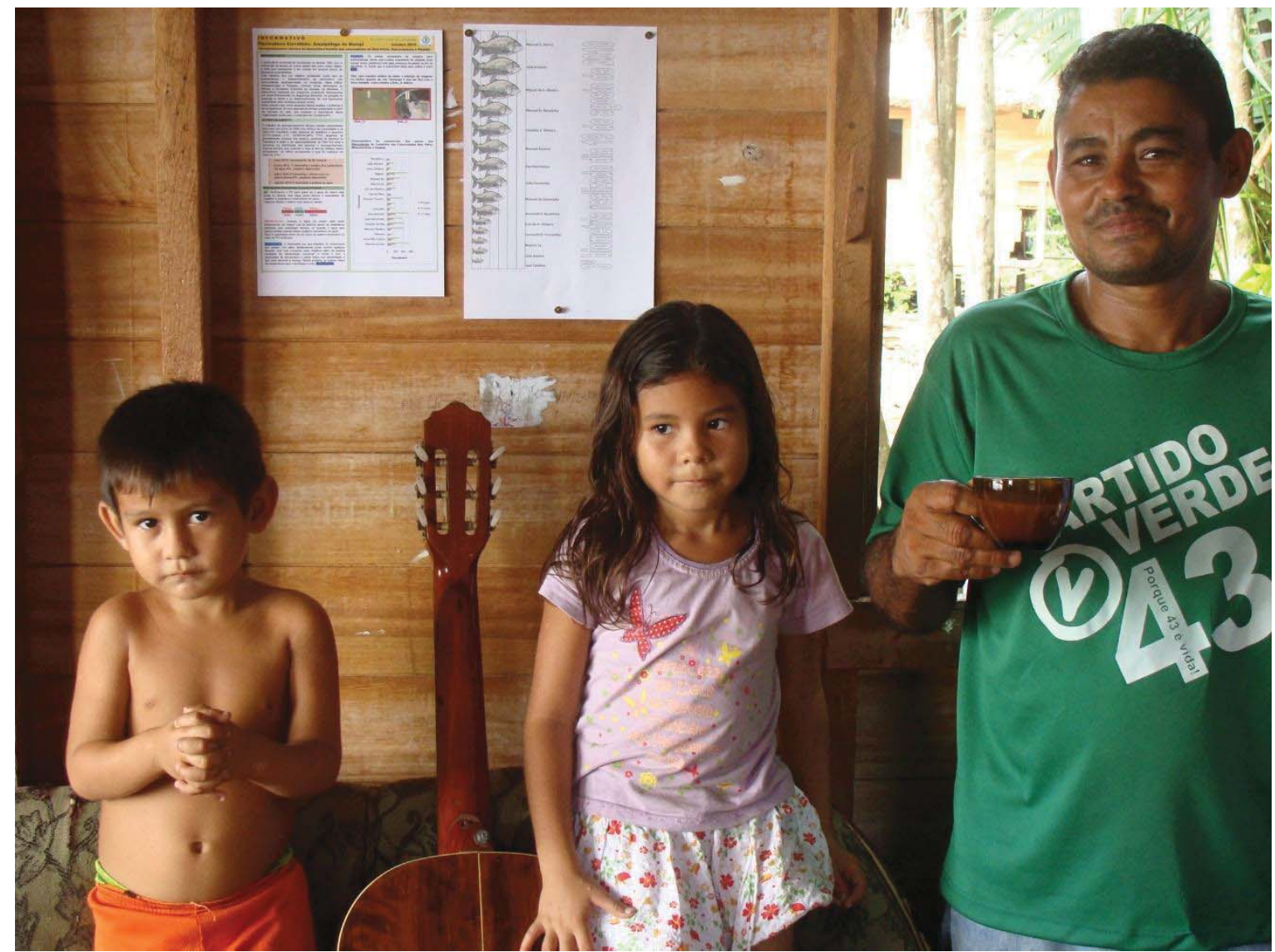

Fonte: Emater/PA, ano 2010.

Dentre os principais resultados observados no presente estudo, temos no envolvimento familiar e seu empoderamento com a atividade o de maior relevância. Pois o projeto como já foi abordado anteriormente, previa primariamente os impactos de intervenção da inserção dessa atividade numa realidade essencialmente extrativista. Logo os dados demonstram o nível de envolvimento das comunidades, que favoreceram o alcance dos resultados de cultivo satisfatório para a realidade local. 
Figura 6 - Acompanhamento e apoio das famílias nas biometrias

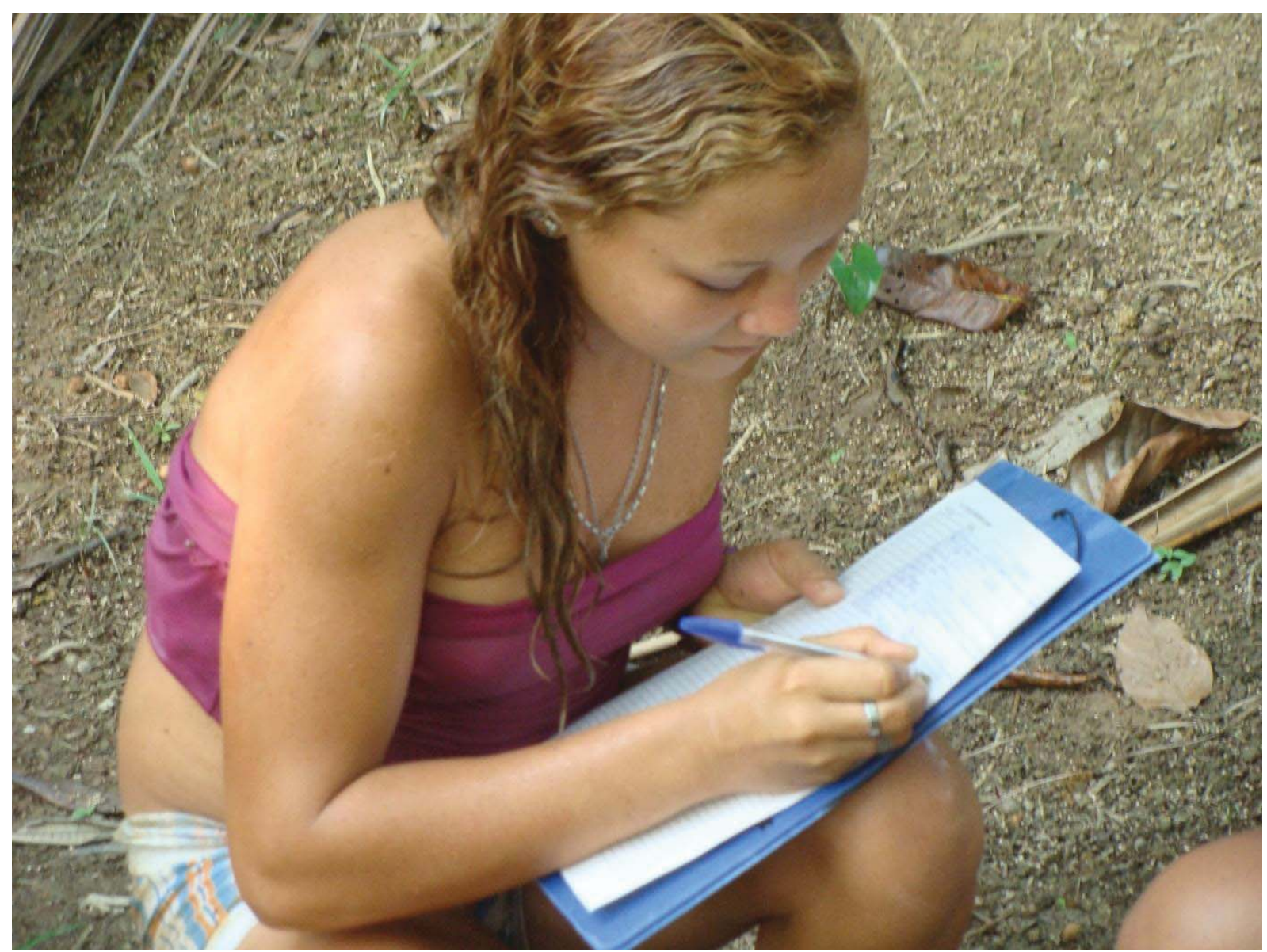

Fonte: Arquivo pessoal da autora, ano 2010.

As 5 biometrias realizadas no período de 9 meses de cultivo demonstraram o acelerado crescimento dos peixes, dado a qualidade e renovação de água no ambiente de cultivo, com a obtenção de indivíduos variando entre 0,8 a 1,2 $\mathrm{Kg}$. Considerado um sucesso a partir dos elementos iniciais, como a falta de experiência dos envolvidos com a atividade, os poucos recursos disponíveis, adequação das técnicas a realidade local, e infraestruturas como principais desafios. 
Figura 7 - Evolução do cultivo por amostragem de famílias.

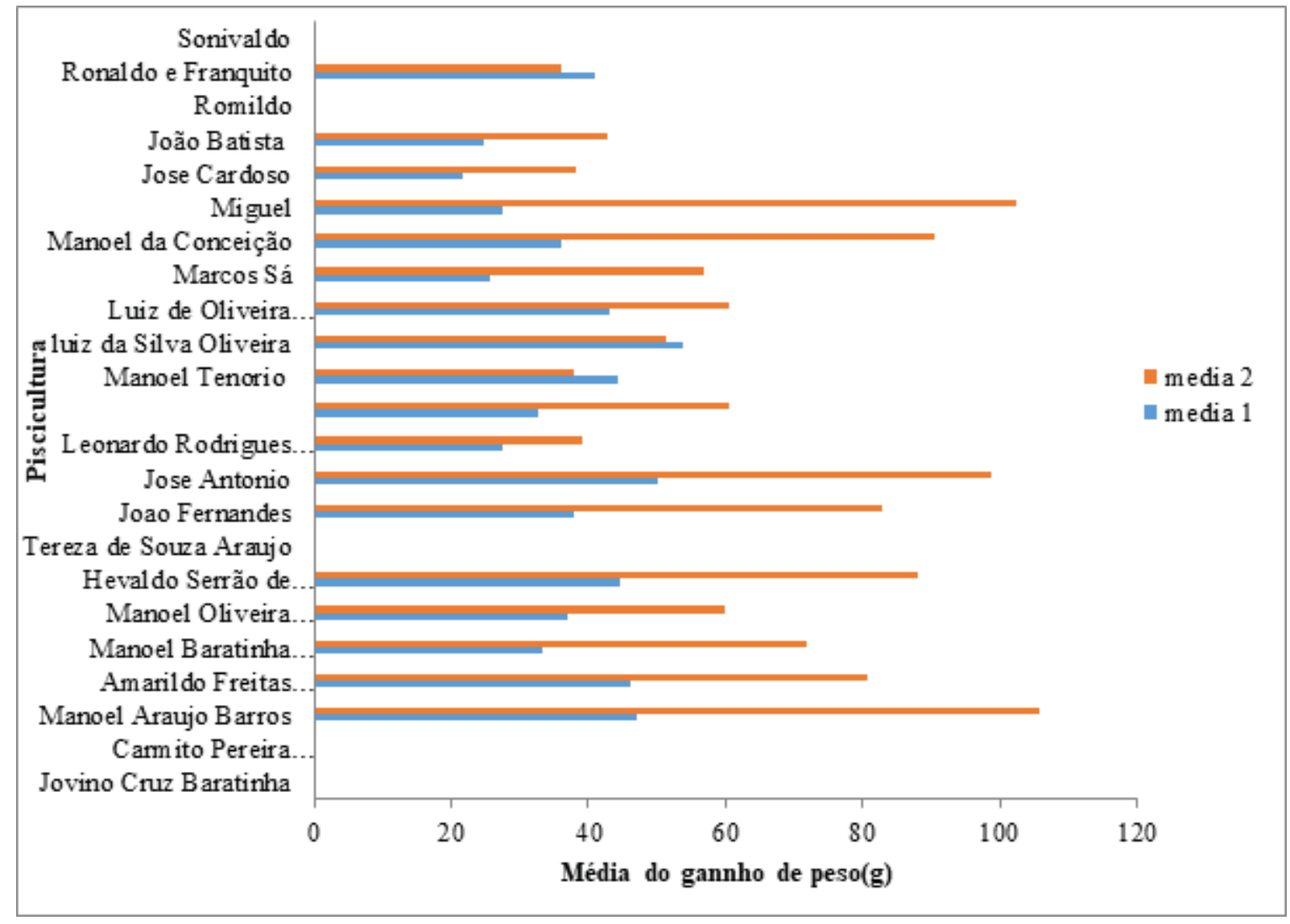

Adaptado a partir de dados obtidos em pesquisa de campo - FEV, 2010.

Considerou-se animador o resultado obtido principalmente pela resposta de crescimento, uma vez que trabalhamos num sistema semi-intensivo, entretanto apesar das condições desfavoráveis de logística e acesso, além de necessidades de adaptações, não diferenciou de resultados de cultivos em condições mais favoráveis. Obedeceu o que foi estabelecido como parâmetros ideias de cultivo para garantir a sustentabilidade da atividade e viabilidade de replicação do projeto para as demais comunidades do município e/ou região

Dentro do quadro negativo do projeto observou a evasão de algumas famílias por não conseguirem se adaptar a rotina da atividade, ficou evidenciado nesse caso a falta de envolvimento na administração de tarefas dentro da unidade familiar, o número de desistência foi reduzido, mas pôde ser constatado a importância da coesão entre os membros da família nessa dinâmica.

O projeto dentro das palestras e encontros periódicos abordou a temática ambiental que foi exaustivamente trabalhada dentro dessas comunidades, demonstrando a importância deles como parte integrante do processo e agentes multiplicadores de práticas e atitudes sustentáveis. 


\section{CONCLUSÃO}

Considerando o objetivo do projeto em levar experiência positiva, de inserção da atividade de piscicultura em comunidades ribeirinhas do município de Curralinho obteve-se resultados amplamente satisfatórios. Diante de tantos aspectos a serem considerados, no cenário de comunidades originalmente extrativistas. A prática incentivou não somente novas formas de apropriação de renda a essas famílias, como também garantia de segurança alimentar.

Além da percepção da necessidade da presença do Estado junto dessas comunidades, com incentivos específicos para desenvolvimento de sistemas produtivos, que garantam a sustentabilidade dessas famílias, sem alterar a sua lógica patrimonial cultural.

\section{REFERÊNCIAS}

BALDISSEROTO, Bernardo, \& GOMES, Levy de Carvalho (2005). Espécies Nativas para a Piscicultura no Brasil. Editora da UFSM, Santa Maria-RS, 2005. 470pp. ISBN 85-7391064-X.

BRASIL. 2008. Plano de desenvolvimento territorial sustentável do arquipélago do Marajó. Grupo executivo do estado do Pará para o Plano Marajó - Decreto de 30 de julho de 2007. Brasilia. 296p. Disponível em:

<http://www.integracao.gov.br/download/download.asp?endereco=/pdf/desenvolvimentoregio nal/plano_marajo.pdf\&nome_arquivo=plano_marajo.pdf $>$. Acesso em: 10 novembro 2018

FERNANDES, Daniel dos Santos(abril/junho de 2015). Em busca do desenvolvimento Sustentável : Construção de Relações Sociais em comunidades ribeirinhas da Amazônia. CIÊNCIA E CULTURA, v 6 n 2.

FERNANDES, José Guilherme dos Santos, \& FERNANDES, Daniel dos Santos (2015). A "experiência próxima": saber e conhecimento em povos tradicionais. Espaço Ameríndio, Porto Alegre V.9 n.1 2015, p 127-150.

Disponível em: <https://seer.ufrgs.br/EspacoAmerindio/article/view/53593> Acesso em: 13 novembro 2018

GOMES, Andréa. (2013). Boas práticas de piscicultura familiar. Seminário de ensino, pesquisa e extensão da UFFS, Seminário de Ensino, Pesquisa e Extensão da UFFS, Laranjeiras do Sul V 3 p. 34-49.

INSTITUTO BRASILEIRO DE GEOGRAFIA E ESTATÍSTICA, Município de Curralinho. Disponível em: <https://biblioteca.ibge.gov.br/index.php/bibliotecacatalogo?view $=$ detalhes $\& i d=614250>$. Acesso em: 10 novembro 2018 
INSTITUTO CHICO MENDES DA BIODIVERSIDADE. RESEX Marinha Terra Grande Pracuúba. Disponível em: http://www.icmbio.gov.br/portal/unidadesdeconservacao/biomasbrasileiros/amazonia/unidades-de-conservacao-amazonia/2046-resex-terra-grande-pracuuba.

Acesso em: 12 novembro 2018.

ONO, Eduardo KUBTIZA, Fernando. Piscicultura familiar, uma alternativa para a segurança alimentar. Panorama da aquicultura, v20 n117 jan/fev 2010 14-23.

SALERA JÚNIOR, Giovanni. Reserva Extrativista Terra Grande Pracuúba. Textos Ensaios. Março/2014.

Disponível em: <http://www.recantodasletras.com.br/ensaios/2777903>. Acesso em: 14 novembro 2018.

SILVA JUNIOR, Walmiro Amador, (2016). A várzea esta para peixe: viabilidade sócio econômica da piscicultura na Bacia do Aricurá, Cametá, Pará. Belém. Dissertação apresentada Programa de Pós-Graduação em Agricultura Amazônica, Núcleo de Ciências Agrárias e Desenvolvimento Rural, UFPA, 2016

SILVA JUNIOR, Walmiro Amador, (2016). A varzea esta para peixe: viabilidade socioeconomica da piscicultura na Bacia do Aricurá, Cametá, Pará, Belém, Dissertação apresentada Programa de Pós-Graduação em Agricultura Amazônica, Núcleo de Ciências Agrárias e Desenvolvimento Rural, UFPA, 2016

SOUZA, Murilo Mendonça Oliveira. A utilização de metodologias de diagnóstico e planejamento participativo em assentamentos rurais: diagnóstico rural rápido participativo drp. In . Em Extensão, Uberlândia, 2009 v 8 n 1 p 34-47. 